\title{
ANALISIS PENGARUH SERVICE QUALITY DAN SISTEM INFORMASI SEKOLAH TERHADAP CUSTOMER SATISFACTION YANG BERDAMPAK PADA CUSTOMER LOYALTY STUDI KASUS SEKOLAH XYZ
}

\author{
Roni Kurniawan \\ Information Systems Department, School of Information Systems, Binus University \\ Jl. K.H. Syahdan No. 9, Palmerah, Jakarta Barat 11480 \\ ronikurniawan.binus@yahoo.com
}

\begin{abstract}
Education has a strategic role in preparing qualified future generations. Education has business potential that is reliable and promising, considering the timeless education, as well as the expectations of every parent to their children to have the access to the best education. Evolving world of education today is demonstrated by the high rate of growth of established schools, especially private schools. Parents today are more savvy and critical in determining the best school for their children, taking into account various aspects, ranging from excellent schools, curriculum, learning systems, the facility to activities that make their children good personality and smart. A more selective attitude that makes private education institutions now have to be more innovative in order to compete. This study was conducted to determine how big the Service Quality and Information Systems School, affect Customer Satisfaction, which will have an impact on Customer Loyalty (Case Study at XYZ School). The study was conducted with data collection techniques in the form of questionnaires to a total of 100 respondents, using descriptive statistical calculations, where the data were analyzed by using electronic data processing methods with the support of SPSS 17.0 To measure the influence of independent variables on the dependent variable, then the path analysis (path analysis) was used. The results showed that the Service Quality and Information Systems School were contributing together, and significant in Customer Satisfaction. Service Quality, Information Systems and Customer Satisfaction of school together contribute significantly to Customer Loyalty.
\end{abstract}

Keywords: Service Quality, Information System, Customer Satisfaction, Customer Loyalty

\begin{abstract}
ABSTRAK
Pendidikan memiliki peran strategis menyiapkan generasi masa depan yang berkualitas. Pendidikan memiliki potensi bisnis yang dapat diandalkan dan menjanjikan, mengingat pendidikan tidak lekang oleh waktu, serta harapan setiap orang tua agar putra-putrinya dapat mengenyam pendidikan terbaik. Maraknya perkembangan dunia usaha pendidikan dewasa ini, ditunjukkan dengan semakin tingginya tingkat pertumbuhan sekolah yang didirikan terutama sekolah swasta. Orang tua saat ini lebih cerdas dan kritis dalam menentukan sekolah terbaik bagi putra-putrinya, dengan mempertimbangkan berbagai aspek, mulai dari sekolah unggulan, kurikulum, sistem pembelajaran, fasilitas hingga kegiatan yang menjadikan anak mereka berkepribadian baik dan cerdas. Sikap yang lebih selektif itu yang membuat institusi pendidikan swasta kini harus lebih inovatif agar dapat bersaing. Penelitian ini dilakukan untuk mengetahui seberapa besar Service Quality dan Sistem Informasi Sekolah, mempengaruhi Customer Satisfaction, yang akan berdampak pada Customer Loyalty (Studi Kasus pada Sekolah XYZ). Penelitian dilakukan dengan teknik pengumpulan data berupa kuesioner kepada sejumlah 100 responden, dengan menggunakan metode deskriptif dengan perhitungan statistik, dimana data dianalisis dengan menggunakan metode pengolahan data secara elektronik dengan dukungan program SPSS 17.0 untuk mengukur besarnya pengaruh variabel independent terhadap variable dependent, maka analisis jalur (Path Analysis) digunakan. Hasil penelitian menunjukkan bahwa Service Quality dan Sistem Informasi Sekolah, berkontribusi secara bersama, dan signifikan pada Customer Satisfaction. Service Quality, Sistem Informasi Sekolah dan Customer Satisfaction, berkontribusi bersama dan signifikan terhadap Customer Loyalty.
\end{abstract}

Kata kunci: Service Quality, Sistem Informasi, Customer Satisfaction, Customer Loyalty 


\section{PENDAHULUAN}

Pendidikan memiliki peran strategis menyiapkan generasi masa depan yang berkualitas. Dunia bisnis dalam bidang pendidikan merupakan salah satu potensi bisnis yang bisa diandalkan dan menjanjikan, mengingat pendidikan tidak lekang oleh waktu, serta harapan setiap orang tua agar putraputrinya dapat mengenyam pendidikan terbaik. Hal tersebut merupakan salah satu faktor yang mendorong semakin berkembangnya dunia usaha pendidikan. Seiring berjalannya waktu, calon orang tua peserta didik menjadi lebih cermat dan teliti dalam menentukan sekolah sebagai mitra pendidikan bagi putra-putri mereka. Orang tua saat ini lebih cerdas dan kritis dalam menentukan sekolah terbaik bagi putra-putrinya, dengan mempertimbangkan berbagai aspek, mulai dari sekolah unggulan, kurikulum, sistem pembelajaran, fasilitas hingga kegiatan yang menjadikan anak mereka berkepribadian baik dan cerdas. Sikap yang lebih selektif itu yang membuat institusi pendidikan swasta kini harus lebih inovatif agar dapat bersaing.

Keberhasilan perusahaan atau institusi dalam mempengaruhi pelanggan dalam mengambil keputusan untuk membeli, sangat dipengaruhi oleh upaya menumbuhkan kepuasan pelanggan melalui kualitas layanan (service quality). Kepuasan pelanggan terhadap perusahaan atau institusi merupakan suatu aset yang tak ternilai bagi institusi. Kepercayaan dari pelanggan juga dapat dipandang sebagai dasar dalam hubungan dengan pelanggan. Meningkatnya intensitas persaingan dan jumlah pesaing menuntut institusi pendidikan untuk selalu memperhatikan kebutuhan dan keinginan pelanggan, serta berusaha memenuhi harapan pelanggan dengan cara memberikan pelayanan yang lebih memuaskan daripada yang dilakukan oleh pesaing. Dengan melihat fenomena yang terjadi saat ini, Sekolah XYZ terus berupaya untuk meningkatkan kualitas, baik dalam aspek akademis maupun pelayanannya kepada orang tua dan siswa. Dengan dukungan Sistem Informasi yang baik serta dilengkapi dengan layanan yang berkualitas, diharapkan mendorong timbulnya kepuasan pelanggan. Kepuasan pelanggan yang telah dibangun dengan baik akan mendorong pelanggan tersebut untuk terjadinya penggunaan kembali barang atau jasa yang ditawarkan oleh penyedia jasa (loyal), dan juga memberikan rekomendasi kepada orang lain.

Persaingan ketat di antara institusi-institusi pendidikan mempengaruhi suatu institusi pendidikan dalam mempertahankan pangsa pasar, institusi harus bekerja keras untuk memuaskan pelanggan serta mempertahankan loyalitas pelanggannya. Pengalaman pelanggan dalam menggunakan dan menikmati kepuasaan jasa yang telah diberikan tersebut akan membuat pelanggan membeli barang atau jasa yang sama (loyal). Karakteristik loyalitas pelanggan didasarkan pada dimensi perilaku dan sikap, yaitu mempertimbangkan suatu produk atau jasa sebagai pilihan utama di masa mendatang, termasuk merekomendasikan hal-hal positif mengenai suatu perusahaan/institusi kepada orang lain.

Itulah sebabnya di saat ketatnya persaingan antar sekolah saat ini mendorong Sekolah XYZ untuk menggunakan berbagai macam strategi dengan melakukan program layanan yang berkualitas dan membentuk citra sekolah dengan baik untuk memberikan kepuasan pelanggan yang pada akhirnya menumbuhkan loyalitas pelanggan serta menjaga loyalitas pelanggannya tersebut, sehingga timbul kecintaan terhadap sekolah, dengan demikian diharapkan orang tua akan menyekolahkan seluruh putra/putrinya di seluruh jenjang pendidikan yang tersedia di Sekolah XYZ dan tidak beralih ke sekolah pesaing, serta dengan kepuasan yang dimiliki oleh pelanggan akan mereferensikan sekolah ini kepada orang lain.

Dengan demikian loyalitas pelanggan adalah kesetiaan pelanggan terhadap produk dan jasa yang diberikan oleh perusahaan/institusi dalam jangka waktu yang lama dengan apresiasi yang positif, yaitu secara kontinu menggunakan produk dan jasa tersebut dan merekomendasikannya kepada orang lain. Berkaitan dengan penjelasan di atas, maka dilakukan penelitian dengan tujuan untuk menganalisis Pengaruh Service Quality dan Sistem Informasi Sekolah terhadap Customer Satisfaction yang berdampak pada Customer Loyalty (Studi Kasus pada Sekolah XYZ). 
Berdasarkan latar belakang sebagaimana telah terurai di atas tadi maka dapat dirumuskan permasalahan sebagai berikut: (1) Apakah terdapat pengaruh Service Quality terhadap Customer Satisfaction? (2) Apakah terdapat pengaruh Sistem Informasi Sekolah terhadap Customer Satisfaction? (3) Apakah terdapat pengaruh Service Quality dan Sistem Informasi Sekolah terhadap Customer Satisfaction? (4) Apakah terdapat pengaruh Service Quality terhadap Customer Loyalty? (5) Apakah terdapat pengaruh Sistem Informasi Sekolah terhadap Customer Loyalty? (6) Apakah terdapat pengaruh Customer Satisfaction terhadap Customer Loyalty? (7) Apakah terdapat pengaruh Service Quality, Sistem Informasi Sekolah dan Customer Satisfaction terhadap Customer Loyalty?

Dengan adanya perumusan masalah sebagaimana terurai di atas maka beberapa tujuan yang akan dicapai, antara lain: (1) Untuk mengetahui pengaruh Service Quality terhadap Customer Satisfaction. (2) Untuk mengetahui pengaruh Sistem Informasi Sekolah terhadap Customer Satisfaction. (3) Untuk mengetahui pengaruh Service Quality dan Sistem Informasi Sekolah terhadap Customer Satisfaction. (4) Untuk mengetahui pengaruh Service Quality terhadap Customer Loyalty. (5) Untuk mengetahui pengaruh Sistem Informasi Sekolah terhadap Customer Loyalty. (6) Untuk mengetahui pengaruh Customer Satisfaction terhadap Customer Loyalty. (7) Untuk mengetahui pengaruh Service Quality, Sistem Informasi Sekolah dan Customer Satisfaction terhadap Customer Loyalty.

\section{Tinjauan Pustaka}

Pengertian kualitas pelayanan berpusat pada upaya pemenuhan keinginan pelanggan serta ketepatan penyampaiannya untuk membarengi harapan pelanggan. Kotler \& Keller (2012) menyatakan bahwa menurut The American Society for Quality's definition: "Quality is the totality of features and characteristics of a product or service that bear on its ability to satisfy stated or implied needs" kualitas merupakan totalitas fitur dan karakteristik dari suatu produk atau jasa yang mengandung kemampuannya untuk memuaskan kebutuhan yang dinyatakan atau tersirat. Definisi ini jelas berpusat kepada pelanggan. Dapat dikatakan penjual telah memberikan kualitas jika produk atau jasanya memenuhi atau melebihi ekspektasi pelanggan.

Menurut Wyckof dalam Tjiptono (2005), “Kualitas Pelayanan adalah tingkat keunggulan yang diharapkan dan pengendalian atas tingkat keunggulan tersebut untuk memenuhi keinginan pelanggan”. Dengan kata lain, ada dua faktor utama yang mempengaruhi kualitas pelayanan, yaitu: expected service dan perceived service. Jika pelayanan yang diterima dan yang dirasakan sesuai dengan yang diharapkan maka kualitas pelayanan dipersepsikan baik. Jika pelayanan yang diterima melampaui harapan pelanggan maka kualitas pelayanan dipersepsikan sebagai kualitas ideal dan begitu juga sebaliknya, jika pelayanan yang diterima lebih rendah dari yang diharapkan maka kualitas pelayanan dipersepsikan buruk. Dengan demikian baik atau tidaknya kualitas pelayanan tergantung pada penyedia pelayanan dalam memenuhi harapan pelanggan.

Menurut Gronross dalam Tjiptono (2005), kualitas total suatu pelayanan terdiri dari tiga komponen yaitu: technical quality (kualitas output pelayanan yang diterima pelanggan) dan functional quality (kualitas cara penyampaian suatu pelayanan). Berdasarkan beberapa pengertian kualitas atau mutu di atas maka dapat disimpulkan bahwa kualitas adalah gabungan seluruh karakteristik suatu produk atau jasa yang menampilkan kemampuannya untuk dapat memenuhi dan sesuai dengan kebutuhan pelanggan.

Sistem adalah sekelompok elemen-elemen yang terintegrasi dengan maksud yang sama untuk mencapai suatu tujuan (McLeod, 2004). Informasi adalah data yang telah dimanipulasi sehingga lebih berharga. Informasi harus memiliki nilai atau masih berupa data yang berguna bagi orang-orang yang membutuhkan. Definisi umum dari informasi adalah "Informasi adalah data yang telah diolah menjadi suatu bentuk yang bagi penerimanya dan bermanfaat bagi penerimanya dalam mengambil keputusan 
pada saat ini atau masa yang akan datang” (Jogiyanto, 2005). Definisi lain mengenai informasi menurut adalah: "Data yang telah diproses atau data yang memiliki arti” (McLeod, 2004).

Telah diketahui bahwa informasi merupakan hal yang sangat penting bagi manajemen di dalam proses pengambilan keputusan. Informasi dapat diperoleh dari sistem informasi (information system) atau disebut juga dengan processing systems atau information processing system atau information-generating systems. Sistem informasi didefinisikan oleh Jogiyanto (2005) adalah "Sistem informasi adalah suatu sistem di dalam suatu organisasi yang mempertemukan kebutuhan pengolahan transaksi harian, mendukung operasi, bersifat manajerial dan kegiatan strategi dari suatu organisasi dan menyediakan pihak luar tertentu dengan laporan-laporan yang diperlukan”.

Saat ini perhatian terhadap kepuasan dan ketidakpuasan pelanggan telah semakin besar, karena pada dasarnya tujuan dari suatu perusahaan adalah untuk menciptakan rasa puas kepada para pelanggan. Semakin tinggi tingkat kepuasan pelanggan, maka akan mendatangkan keuntungan yang semakin besar bagi perusahaan, karena pelanggan akan melakukan pembelian ulang terhadap produk perusahaan. Namun, apabila tingkat kepuasan yang dirasakan pelanggan kecil, maka terdapat kemungkinan bahwa pelanggan tersebut akan berpindah ke produk pesaing.

Menurut (Kotler, 2007), kepuasan pelanggan adalah perasaan senang atau kecewa seseorang yang muncul setelah membandingkan kinerja (hasil) produk yang dipikirkan terhadap kinerja (atau hasil) yang diharapkan. Jika kinerja berada di bawah harapan, pelanggan tidak puas. Jika kinerja berada memenuhi harapan, pelanggan puas. Jika kinerja melebihi harapan, pelanggan amat puas atau senang. Sedangkan menurut (Lupiyoadi \& Hamdani, 2006) kepuasan atau ketidakpuasan pelanggan adalah respon pelanggan terhadap evaluasi ketidaksesuaian (disconfirmation) yang dirasakan antara harapan sebelumnya dan kinerja aktual produk yang dirasakan setelah pemakaiannya. Begitu pula menurut Cao \& Chen (2011), "the customer satisfaction is a kind of feeling that whether the product or service has met or surpassed the expectation”, bahwa kepuasan pelanggan merupakan suatu perasaan yang menyatakan bagaimana suatu produk atau jasa telah memenuhi atau melampaui harapan.

Definisi loyalitas pelanggan menurut Andreassen dalam Hasan (2009), menyatakan bahwa perilaku yang terkait dengan merk sebuah produk, termasuk kemungkinan memperbaharui kontrak merk di masa yang akan datang, berapa kemungkinan keinginan pelanggan untuk meningkatkan citra positif suatu produk. Jika produk tidak mampu memuaskan pelanggan, pelanggan akan bereaksi dengan cara exit (pelanggan menyatakan berhenti membeli merk atau produk) dan voice (pelanggan menyatakan ketidakpuasan secara langsung pada perusahaan).

Definisi loyalitas menurut Kotler (2005), menyebutkan bahwa loyalitas pelanggan adalah suatu pembelian ulang yang dilakukan oleh seorang pelanggan karena komitmen pada suatu merek atau perusahaan. Sebenarnya ada banyak faktor yang mempengaruhi suatu pelanggan untuk loyal, antara lain faktor harga: seseorang tentu akan memilih perusahaan atau merek yang menurutnya menyediakan alternatif harga paling murah diantara pilihan-pilihan yang ada. Selain itu ada juga faktor kebiasaan, seseorang yang telah terbiasa menggunakan suatu merek atau perusahaan tertentu maka kemungkinan untuk berpindah ke pilihan yang lain akan semakin kecil.

Loyalitas secara umum dapat diartikan kesetiaan seseorang atas suatu produk, baik barang maupun jasa tertentu. Loyalitas pelanggan merupakan manifestasi dan kelanjutan dari kepuasan pelanggan dalam menggunakan fasilitas maupun jasa pelayanan yang diberikan oleh perusahaan, serta untuk tetap menjadi pelanggan dari perusahaan tersebut (Foedjiwati \& Samuel, 2005). Menurut (Tjiptono, 2008), loyalitas pelanggan adalah komitmen pelanggan terhadap suatu merek, toko, atau pemasok (perusahaan), berdasarkan sikap yang sangat positif dan tercermin dalam pembelian ulang yang konsisten. 
Cao \& Chen (2011) menyatakan bahwa "the service quality is closely related to the customer satisfaction and loyalty degree. It has the direct and postive influence on customer satisfaction", bahwa kualitas pelayanan berkaitan erat dengan kepuasan pelanggan dan tingkat loyalitas. Ia memiliki pengaruh langsung dan positif terhadap kepuasan pelanggan. Deng (2010) menyatakan bahwa "Customer satisfaction, which refers to 'the summary psychological state resulting when the emotion surrounding disconfirmed expectations is coupled with the consumer's prior feelings about the consumption experience', is often considered as an important determinant of repurchase intention and customer loyalty. Berdasarkan pengertian tersebut di atas maka dapat disimpulkan, bahwa loyalitas pelanggan merupakan kesetiaan pelanggan terhadap suatu produk atau jasa perusahaan dengan disertai tindakan untuk membeli kembali dan pelanggan bersedia mengembangkan hubungan kembali.

\section{Tinjauan Obyek Penelitian}

Sekolah XYZ resmi berdiri pada tahun 1994 untuk jenjang TK dan SD, dilanjutkan dengan pembukaan jenjang SMP pada tahun 1998, serta SMA pada tahun 2007. Sekolah XYZ berlokasi di Puri Indah - Jakarta Barat. Sekolah ini didukung oleh 130 orang guru dan 20 karyawan, dimana saat ini sekolah memiliki total siswa sejumlah 1.713 orang. TK, SD, SMP, dan SMA XYZ masing-masing terakreditasi 'A' oleh Badan Akreditasi Nasional di bawah Kemendikbud sebagai penilaian atas kualitas pendidikan yang diselenggarakan oleh sekolah.

Sekolah XYZ mendukung pengembangan talenta dan bakat para siswa-siswinya dengan menyelenggarakan beberapa acara dan kegiatan edukatif, seperti Leadership Day, Edufair, Seminar Bakat, Pameran Hasil Kreativitas Siswa, Pentas Seni, Thanksgiving day, Joyful day, Happy day dan lain-lain. Sekolah XYZ Puri berhasil mendampingi siswa-siswinya untuk meraih prestasi, baik di tingkat nasional maupun di internasional.

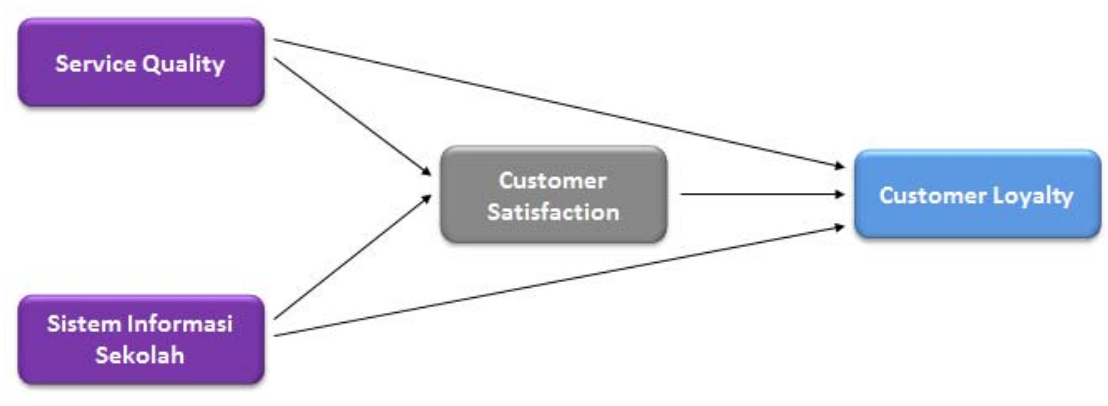

Gambar 1 Skema Kerangka Penelitian

(Sumber : diolah oleh penulis)

Hipotesis yang diuji dalam penelitian ini adalah sebagai berikut: (1) $\mathrm{Ho}_{1}$ : Terdapat pengaruh positif dan signifikan Service Quality terhadap Customer Satisfaction. (2) $\mathrm{Ho}_{2}$ : Terdapat pengaruh positif dan signifikan Sistem Informasi Sekolah terhadap Customer Satisfaction. (3) $\mathrm{Ho}_{3}$ : Terdapat pengaruh positif dan signifikan Service Quality dan Sistem Informasi Sekolah terhadap Customer Satisfaction. (4) $\mathrm{Ho}_{4}$ : Terdapat pengaruh positif dan signifikan Service Quality terhadap Customer Loyalty. (5) Ho Ho $_{5}$ Terdapat pengaruh positif dan signifikan Sistem Informasi Sekolah terhadap Customer Loyalty. (6) $\mathrm{Ho}_{6}$ : Terdapat pengaruh positif dan signifikan Customer Satisfaction terhadap Customer Loyalty. (7) $\mathrm{Ho}_{7}$ : Terdapat pengaruh positif dan signifikan Service Quality, Sistem Informasi Sekolah dan Customer Satisfaction terhadap Customer Loyalty 


\section{METODE}

Penelitian yang dilakukan merupakan penelitian dengan menggunakan metode Deskriptif dan Asosiatif. Menurut Nazir (2005), penelitian deskriptif adalah suatu metode dalam meneliti status sekelompok manusia, suatu objek, suatu set kondisi, suatu sistem pemikiran ataupun suatu kelas peristiwa pada masa sekarang. Sedangkan penelitian Asosiatif merupakan metode untuk mencari korelasi atau hubungan kausal (menanyakan apakah terdapat hubungan atau apakah variabel independen mempengaruhi variabel dependen).

Penelitian yang dilakukan di Sekolah XYZ ini adalah penelitian ilmiah yang bertujuan untuk memahami suatu masalah secara lebih mendalam dalam suatu organisasi jasa yang berguna dalam pengembangan ilmu manajemen tanpa bermaksud menerapkan hasilnya, maka penelitian ini dinamakan penelitian dasar (murni). Pengumpulan data melalui kuesioner untuk penelitian ini dilakukan dari tanggal 01-30 November 2013 di Sekolah XYZ. Populasi dalam penelitian ini merupakan orang tua dari para siswa Sekolah XYZ dari tingkat Taman Kanak-kanak (TK) hingga Sekolah Menengah Atas (SMA) yang berjumlah 1.500 orang tua atau wali siswa. Untuk menentukan jumlah sampel minimal yang perlu diambil untuk melakukan penelitian, dapat melakukan dari Tora Yamane atau Slovin (Ridwan dan Engkos, 2007). Jumlah sampel yang dibutuhkan dalam penelitian ini adalah sebanyak 100 responden yang merupakan orang tua atau wali siswa dari Sekolah XYZ.

Terdapat beberapa metode analisis yang digunakan. Analisis diawali pada instrumen penelitian yaitu kuesioner diolah dengan menggunakan uji validitas dan reliabilitas setelah itu diteruskan dengan uji normalitas data. Kemudian pengolahan data akan dilanjutkan dengan menggunakan analisis korelasi dan regresi, analisis deskriptif, serta uji asumsi dengan menggunakan uji path analysis. Pengolahan data tersebut dilakukan untuk menjawab beberapa tujuan penelitian sehingga dapat diperoleh kesimpulan yang mengarah pada pembuatan saran.

Model path analysis digunakan untuk menganalisi pola hubungan antar variabel dengan tujuan untuk mengetahui pengaruh langsung maupun tidak langsung seperangkat variabel bebas (eksogen) terhadap variabel terikat (endogen). Teknik analisis jalur ini akan digunakan dalam menguji besarnya sumbangan (kontribusi) yang ditunjukan oleh koefisien jalur pada setiap diagram jalur hubungan kausal antara variabel $\mathrm{X}_{1}$ dan $\mathrm{X}_{2}$ terhadap $\mathrm{Y}$ serta dampaknya kepada $\mathrm{Z}$. Analisis korelasi dan regresi yang merupakan dasar dari perhitungan koefisien jalur.

Ridwan dan Kuncoro (2007) yang mengutip Al Rasyid dalam Sitepu (1994, 24) mengatakan bahwa dalam penelitian sosial tidak semata-mata hanya mengungkapkan hubungan variabel sebagai terjemahan statistik dari hubungan antara variabel alami, tetapi terfokus pada upaya untuk mengungkapkan hubungan kausal antar variabel.

\section{HASIL DAN PEMBAHASAN}

\section{Profil Responden} berikut.

Karakteristik responden yang menjadi subjek dalam penelitian ini dapat dilihat dalam tabel 
Tabel 1 Profil Responden

\begin{tabular}{|c|c|c|c|}
\hline Pembagian Profil & Uraian Profil & Jumlah & Presentase \\
\hline \multirow[t]{3}{*}{ Jenis Kelamin } & Pria & 42 orang & $42 \%$ \\
\hline & Wanita & 58 orang & $58 \%$ \\
\hline & 21-30 tahun & 12 orang & $12 \%$ \\
\hline \multirow[t]{3}{*}{ Usia } & 31-40 tahun & 42 orang & $42 \%$ \\
\hline & 41-50 tahun & 20 orang & $20 \%$ \\
\hline & $>51$ tahun & 26 orang & $26 \%$ \\
\hline \multirow[t]{2}{*}{ Profesi } & Karyawan Swasta & 65 orang & $65 \%$ \\
\hline & Wirausaha & 35 orang & $35 \%$ \\
\hline \multirow[t]{4}{*}{ Profesi } & Ibu Rumah Tangga & 18 orang & $18 \%$ \\
\hline & Lainnya & 19 orang & $19 \%$ \\
\hline & SMA/sederajat & 15 orang & $15 \%$ \\
\hline & D1-D3 & 5 orang & $8 \%$ \\
\hline \multirow[t]{3}{*}{ Pendidikan } & S1 & 58 orang & $58 \%$ \\
\hline & $\mathrm{S} 2$ & 18 orang & $18 \%$ \\
\hline & Lainnya & 5 orang & $5 \%$ \\
\hline \multirow[t]{4}{*}{ Alumni Sekolah } & Alumni & 32 orang & $32 \%$ \\
\hline & Non Alumni & 68 orang & $68 \%$ \\
\hline & 1 orang & 10 orang & $02 \%$ \\
\hline & 2 orang & 55 orang & $55 \%$ \\
\hline \multirow[t]{4}{*}{ Jumlah Anak } & 3 orang & 26 orang & $36 \%$ \\
\hline & 4 orang & 7 orang & $7 \%$ \\
\hline & $>4$ orang & 2 orang & $2 \%$ \\
\hline & $\begin{array}{l}\text { Semua anak disekolahkan di } \\
\text { Sekolah XYZ }\end{array}$ & 35 orang & $35 \%$ \\
\hline Anak & $\begin{array}{l}\text { Tidak semua anak } \\
\text { disekolahkan di Sekolah XYZ }\end{array}$ & 65 orang & $65 \%$ \\
\hline
\end{tabular}

\section{Analisis Data}

Dalam analisa pengaruh Service Quality dan Sistem Informasi Sekolah terhadap Customer Satisfaction akan digambarkan dalam sebuah model yang selanjutnya akan disebut dengan sub struktur 1 sebagai berikut:

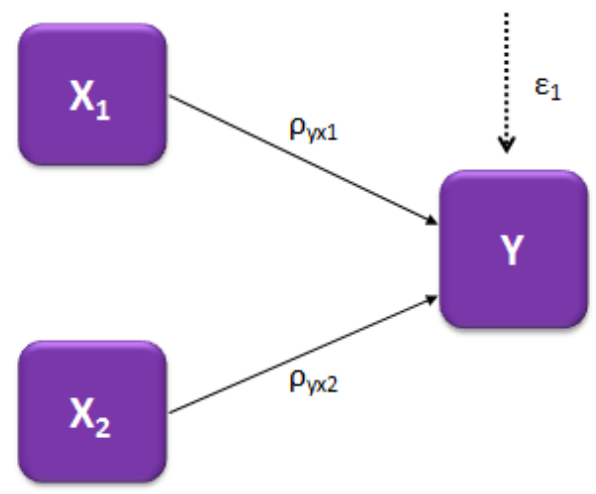

Gambar 2 Sub Struktur 1 
Korelasi Pearson antara variabel $\mathrm{X}_{1}, \mathrm{X}_{2}$ dan $\mathrm{Y}$ di atas dapat diringkas sebagai berikut:

Tabel 2 Sifat Hubungan Korelasi $\mathrm{X}_{1}, \mathrm{X}_{2}$ dan $\mathrm{Y}$

\begin{tabular}{|c|c|l|}
\hline Hubungan antara & Korelasi & Sifat Hubungan \\
\hline $\mathrm{X}_{1}$ dengan $\mathrm{Y}$ & 0,824 & Sangat kuat, Searah dan Signifikan \\
\hline $\mathrm{X}_{2}$ dengan $\mathrm{Y}$ & 0,866 & Sangat kuat, Searah dan Signifikan \\
\hline
\end{tabular}

Selanjutnya dilakukan analisis jalur pada variabel $\mathrm{X}_{1}, \mathrm{X}_{2}$ dan $\mathrm{Y}$, harus diuji linieritas hubungan antara ketiga variabel tersebut.

Tabel 3 Rangkuman Hasil Koefisien Jalur Sub Struktur 1

\begin{tabular}{|l|c|c|c|c|c|}
\hline $\begin{array}{c}\text { Pengaruh } \\
\text { antar Variabel }\end{array}$ & $\begin{array}{c}\text { Koefisien } \\
\text { Jalur (beta) }\end{array}$ & Nilai Sig & $\begin{array}{c}\text { Hasil } \\
\text { Pengujian }\end{array}$ & $\begin{array}{c}\text { Koefisien } \\
\text { Determinasi }\end{array}$ & $\begin{array}{c}\text { Koefisien Variabel } \\
\text { lain }\left(\rho_{\gamma} \varepsilon_{1}\right)\end{array}$ \\
\hline $\mathrm{X}_{1}$ terhadap $\mathrm{Y}$ & 0.407 & 0,000 & Ho ditolak & \multirow{2}{*}{$0,825=82,5 \%$} & \multirow{2}{*}{0,418} \\
\hline $\mathrm{X}_{2}$ terhadap $\mathrm{Y}$ & 0,566 & 0,000 & Ho ditolak & & \\
\hline
\end{tabular}

Dengan demikian diperoleh diagram jalur Sub Struktur 1, namun disajikan dengan nilai koefisien jalur yang telah dapat melalui analisa data sehingga model Sub Struktur 1 menjadi :

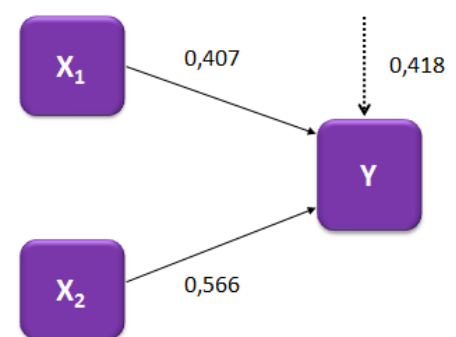

Gambar 3 Sub Struktur 1 beserta Koefisien Jalur

Jadi dapat diperoleh persamaan struktural Sub Struktur 1:

$$
\begin{aligned}
& Y=\rho_{Y X 1} X_{1}+\rho_{Y X 2} X_{2}+\varepsilon_{1} \\
& Y=0,407 X_{1}+0,566 X_{2}+0,418 \varepsilon_{1} \text { dimana } R^{2}=0,825
\end{aligned}
$$

Dari persamaan struktural Sub Struktur 1 dapat diartikan bahwa: (1) Customer Satisfaction (Y) dipengaruhi oleh variabel Service Quality $\left(\mathrm{X}_{1}\right)$ dan Sistem Informasi Sekolah $\left(\mathrm{X}_{2}\right)$ Sekolah XYZ Puri secara simultan sebesar $82,5 \%$ dan sisanya sebesar $17,5 \%$ dipengaruhi oleh variabel-variabel lain di luar penelitian. (2) Setiap peningkatan nilai Service Quality $\left(\mathrm{X}_{1}\right)$ sebesar satu, maka nilai Customer Satisfaction (Y) juga akan naik sebesar 0,407. Begitu juga sebaliknya, setiap penurunan Service Quality $\left(\mathrm{X}_{1}\right)$ sebesar 1, maka nilai Customer Satisfaction (Y) juga akan turun sebesar 0,407. (3) Setiap peningkatan nilai Sistem Informasi Sekolah $\left(\mathrm{X}_{2}\right)$ sebesar satu, maka nilai Customer Satisfaction (Y) juga akan naik sebesar 0,566. Begitu juga sebaliknya, setiap penurunan Sistem Informasi Sekolah $\left(\mathrm{X}_{2}\right)$ sebesar 1, maka nilai Customer Satisfaction (Y) juga akan turun sebesar 0,566. 
Selanjutnya akan dianalisa dampak implementasi Service Quality $\left(\mathrm{X}_{1}\right)$ dan Sistem Informasi Sekolah $\left(\mathrm{X}_{2}\right)$ serta Customer Satisfaction (Y) terhadap Customer Loyalty (Z) maka akan ditampilkan terlebih dahulu Sub Struktur yang kemudian disebut sebagai Sub Struktur 2 dengan model sebagai berikut:

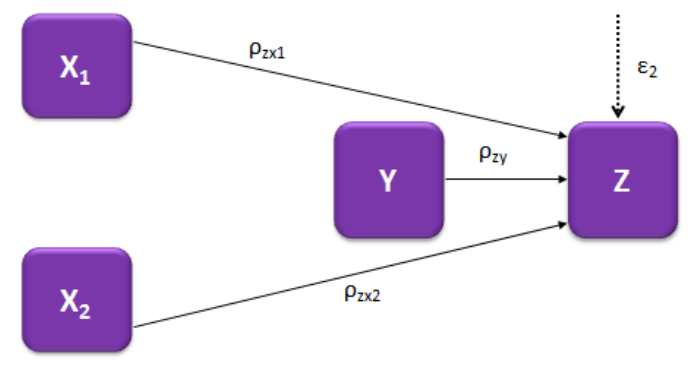

Gambar 4 Sub Struktur 2

Hasil Uji Korelasi Pearson $\mathrm{X}_{1}, \mathrm{X}_{2}, \mathrm{Y}$ dan $\mathrm{Z}$ diatas dapat diringkas sebagai berikut :

Tabel 4 Sifat Hubungan Korelasi $\mathrm{X}_{1}, \mathrm{X}_{2}$, Y dan Z

\begin{tabular}{|c|c|l|}
\hline Hubungan antara & Korelasi & \multicolumn{1}{c|}{ Sifat Hubungan } \\
\hline $\mathrm{X}_{1}$ dengan $\mathrm{Z}$ & 0,744 & Kuat, Searah dan Signifikan \\
\hline $\mathrm{X}_{2}$ dengan $\mathrm{Z}$ & 0,847 & Sangat kuat, Searah dan Signifikan \\
\hline $\mathrm{Y}$ dengan $\mathrm{Z}$ & 0,846 & Sangat kuat, Searah dan Signifikan \\
\hline
\end{tabular}

Selanjutnya dilakukan analisis jalur pada variabel $\mathrm{X}_{1}, \mathrm{X}_{2}, \mathrm{Y}$ dan $\mathrm{Z}$, harus diuji linieritas hubungan antara ketiga variabel tersebut. Bahwa ada koefisien jalur yang tidak signifikan yaitu variabel Service Quality $\left(\mathrm{X}_{1}\right)$, maka perlu diperbaiki melalui model trimming, yaitu mengeluarkan variabel Service Quality $\left(\mathrm{X}_{1}\right)$ yang dianggap hasil dari koefisien jalur yang tidak signifikan dari analisisnya. Kemudian diulang atau diuji lagi variabel eksogen Service Quality $\left(\mathrm{X}_{1}\right)$ tidak diikutsertakan.

Tabel 5 Rangkuman Hasil Koefisien Jalur Sub Struktur 2

\begin{tabular}{|l|c|c|c|c|c|}
\hline $\begin{array}{c}\text { Pengaruh } \\
\text { antar Variabel }\end{array}$ & $\begin{array}{c}\text { Koefisien } \\
\text { Jalur (beta) }\end{array}$ & Nilai Sig & $\begin{array}{c}\text { Hasil } \\
\text { Pengujian }\end{array}$ & $\begin{array}{c}\text { Koefisien } \\
\text { Determinasi }\end{array}$ & $\begin{array}{c}\text { Koefisien Variabel } \\
\text { lain }\left(\boldsymbol{\rho}_{\mathrm{\gamma}} \varepsilon_{1}\right)\end{array}$ \\
\hline $\mathrm{X}_{2}$ terhadap Z & 0.455 & 0,000 & Ho ditolak & \multirow{2}{*}{$0,768=76,8 \%$} & 0,481 \\
\cline { 1 - 4 } Y terhadap Z & 0,452 & 0,000 & Ho ditolak & & \\
\hline
\end{tabular}

Dengan demikian diperoleh diagram jalur Sub Struktur 2, namun disajikan dengan nilai koefisien jalur yang telah dapat melalui analisa data sehingga model Sub Struktur 2 menjadi : 


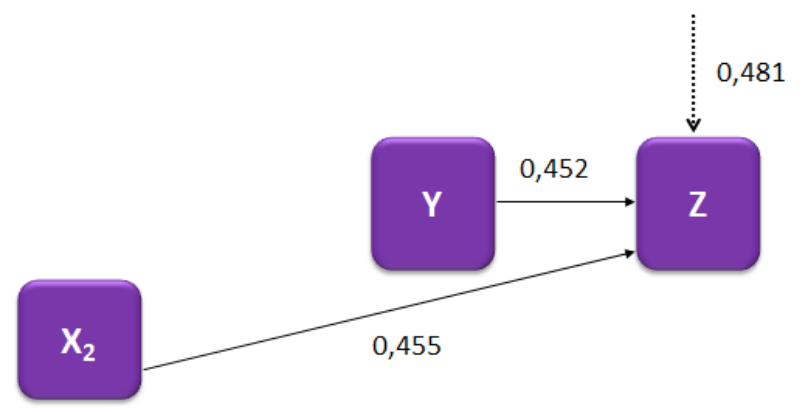

Gambar 5 Sub Struktur 2 beserta Koefisien Jalur

Jadi dapat diperoleh persamaan struktural Sub Struktur 2 :

$$
\begin{aligned}
& Z=\rho_{\mathrm{ZX} 1} X_{1}+\rho_{\mathrm{zX} 2} X_{2}+\rho_{\mathrm{zy}} Y+\rho_{\mathrm{Z}} \varepsilon_{2} \\
& Z=\mathbf{0 , 4 5 5} \mathrm{X}_{2}+\mathbf{0 , 4 5 2} \mathrm{Y}+\mathbf{0 , 4 8 1} \varepsilon_{2} \operatorname{dimana} \mathbf{R}^{\mathbf{2}}=\mathbf{0 , 7 6 8}
\end{aligned}
$$

Dari persamaan struktural Sub Struktur 2 dapat diartikan bahwa: (1) Customer Loyalty (Z) dipengaruhi oleh variabel Sistem Informasi Sekolah $\left(\mathrm{X}_{2}\right)$ dan Customer Satisfaction (Y) Sekolah XYZ secara simultan sebesar 76,8\% dan sisanya sebesar 23,2\% dipengaruhi oleh variabel-variabel lain di luar penelitian. (2) Setiap peningkatan nilai Sistem Informasi Sekolah $\left(\mathrm{X}_{2}\right)$ sebesar satu, maka nilai Customer Loyalty (Z) juga akan naik sebesar 0,455. Begitu juga sebaliknya, setiap penurunan Sistem Informasi Sekolah $\left(\mathrm{X}_{2}\right)$ sebesar 1, maka nilai Customer Loyalty $(\mathrm{Z})$ juga akan turun sebesar 0,455. (3) Setiap peningkatan nilai Customer Satisfaction (Y) sebesar satu, maka nilai Customer Loyalty (Z) juga akan naik sebesar 0,452. Begitu juga sebaliknya, setiap penurunan Customer Satisfaction (Y) sebesar 1, maka nilai Customer Loyalty (Z) juga akan turun sebesar 0,452.

Jadi keseluruhan pengaruh kausal Service Quality $\left(\mathrm{X}_{1}\right)$ dan Sistem Informasi Sekolah $\left(\mathrm{X}_{2}\right)$ terhadap Customer Satisfaction (Y) dan dampaknya terhadap Customer Loyalty (Z) dapat digambarkan dalam model struktur lengkap sebagai berikut:

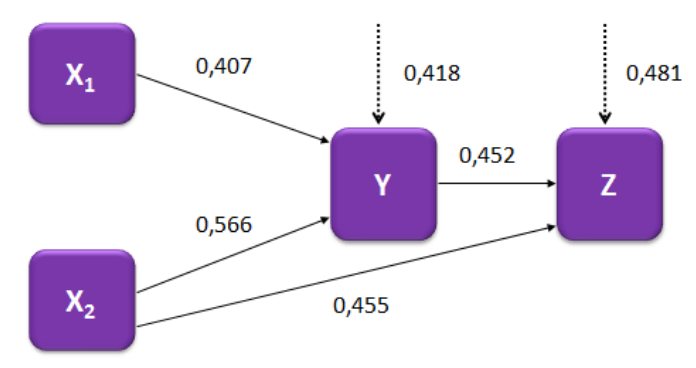

Gambar 6 Struktur lengkap beserta Koefisien Jalur

Untuk melihat pengaruh langsung, tidak langsung dan pengaruh total antar variabel berdasarkan dari hasil yang telah didapat pada analisis Sub Struktur 1 dan 2 dapat dirangkum melalui tabel berikut: 
Tabel 5 Rangkuman Koefisien Jalur $\mathrm{X}_{1}, \mathrm{X}_{2}$, Y terhadap Z

\begin{tabular}{|c|c|c|c|c|c|}
\hline \multirow{2}{*}{$\begin{array}{c}\text { Pengaruh } \\
\text { Variabel }\end{array}$} & \multirow{2}{*}{$\begin{array}{l}\text { Koefisien } \\
\text { Jalur }\end{array}$} & \multicolumn{3}{|c|}{ Pengaruh } & \multirow{2}{*}{$\begin{array}{c}\text { Pengaruh } \\
\text { Bersama } \\
\left.\text { ( } \mathbf{R}^{2} \mathbf{y x k}\right)\end{array}$} \\
\hline & & Langsung & $\begin{array}{c}\text { Tidak langsung } \\
\text { melalui Y }\end{array}$ & Total & \\
\hline $\mathrm{X}_{1}$ terhadap $Y$ & 0,407 & 0,407 & - & 0,407 & - \\
\hline $\mathrm{X}_{2}$ terhadapY & 0,566 & 0,566 & & 0,566 & - \\
\hline $\mathrm{X}_{2}$ terhadap $\mathrm{Z}$ & 0,455 & 0,455 & $0,556 \times 0,455=0,072$ & 0,527 & - \\
\hline $\mathrm{Y}$ terhadap $\mathrm{Z}$ & 0,452 & - & - & 0,452 & - \\
\hline$\varepsilon_{1}$ & 0,418 & - & - & - & - \\
\hline$\varepsilon_{2}$ & 0,481 & - & - & - & - \\
\hline $\mathrm{X}_{1}$ dan $\mathrm{X}_{2}$ & & & - & - & 0,825 \\
\hline $\mathrm{X}_{1}, \mathrm{X}_{2}$ dan $\mathrm{Y}$ & & & & & 0,772 \\
\hline
\end{tabular}

\section{SIMPULAN}

Berdasarkan hasil analisa yang telah diuraikan sebelumnya maka pada penelitian ini dapat disimpulkan bahwa Service Quality $\left(\mathrm{X}_{1}\right)$ berkontribusi positif dan signifikan terhadap Customer Satisfaction (Y). Service Quality ( $\mathrm{X}_{1}$ ) mempengaruhi Customer Satisfaction (Y), artinya jika Service Quality meningkat maka Customer Satisfaction (Y) akan meningkat, begitu pula sebaliknya. Sistem Informasi Sekolah $\left(\mathrm{X}_{2}\right)$ berkontribusi positif dan signifikan terhadap Customer Satisfaction (Y). Sistem Informasi Sekolah $\left(\mathrm{X}_{2}\right)$ mempengaruhi Customer Satisfaction (Y) sebesar 0,566, artinya jika Sistem Informasi Sekolah meningkat maka Customer Satisfaction (Y) akan meningkat, begitu juga sebaliknya.

Service Quality $\left(\mathrm{X}_{1}\right)$ dan Sistem Informasi Sekolah $\left(\mathrm{X}_{2}\right)$ berkontribusi secara bersama dan signifikan terhadap variabel Customer Satisfaction (Y). Besarnya pengaruh variabel Service Quality $\left(\mathrm{X}_{1}\right)$ dan Sistem Informasi Sekolah $\left(\mathrm{X}_{2}\right)$ secara bersama terhadap Customer Satisfaction $(\mathrm{Y})$ adalah 82,5\%. Service Quality $\left(\mathrm{X}_{1}\right)$ tidak berkontribusi secara signifikan terhadap Customer Loyalty (Z). Berkaitan dengan Service Quality yang belum memberikan kontribusi kepada Customer Loyalty maka Sekolah XYZ perlu untuk melakukan penelitian lanjutan untuk mengetahui faktor-faktor pendorong kepuasan orang tua siswa agar terus menyekolahkan putra/putrinya di Sekolah XYZ pada jenjang yang lebih tinggi. Faktor-faktor pendorong tersebut itulah yang diharapkan berdampak semakin positif kepada kepuasan orang tua siswa dan berlanjut pada loyalitas orang tua siswa kepada Sekolah XYZ.

Sistem Informasi Sekolah $\left(\mathrm{X}_{2}\right)$ berkontribusi positif dan signifikan terhadap Customer Loyalty (Z), artinya jika Sistem Informasi Sekolah meningkat maka Customer Loyalty (Z) akan meningkat. Customer Satisfaction (Y) berkontribusi positif dan signifikan terhadap Customer Loyalty (Z). Customer Satisfaction (Y) mempengaruhi Customer Loyalty (Z), artinya jika Customer Satisfaction meningkat maka Customer Loyalty $(\mathrm{Z})$ akan meningkat. Service Quality $\left(\mathrm{X}_{1}\right)$, Sistem Informasi Sekolah $\left(\mathrm{X}_{2}\right)$ dan Customer Satisfaction $(\mathrm{Y})$ berkontribusi secara bersama dan signifikan terhadap variabel Customer Loyalty (Z).

Beberapa hal yang perlu mendapat fokus untuk langkah selanjutnya antara lain adalah Sekolah XYZ perlu melakukan pengembangan secara berkelanjutan (continues improvement) atas Service Quality kepada para pelanggannya, dalam hal ini adalah orang tua siswa. Saat ini Service Quality telah memberikan kontribusi yang positif kepada Customer Satisfaction, namun belum berdampak secara signifikan terhadap Customer Loyalty. Untuk itu Sekolah XYZ dapat menjalankan program Customer Relationship Management (CRM) untuk membangun hubungan yang lebih baik dan bersifat harmonis dengan orang tua dan siswa. 
Sekolah XYZ perlu lebih mengoptimalkan Service Quality melalui program Layanan yang telah dimilikinya saat ini dengan tujuan agar program tersebut mampu mengimplementasikan 5 (lima) dimensi dari jasa yaitu: tangible, reliability, responsiveness, assurance dan empathy. Program Layanan Sekolah tersebut bisa difokuskan pada usaha pengembangan atas fasilitas sekolah, peningkatan kualitas sumber daya manusia (guru dan staf Tata Usaha sekolah) dari Sekolah XYZ.

Seluruh pimpinan, para pendidik dan staf Sekolah XYZ perlu menjaga dengan baik corporate credibility yang telah dibentuk agar terus meningkatkan Customer Satisfaction dan Customer Loyalty semakin baik. Customer Satisfaction menjadi faktor yang penting dan juga menjadi tujuan utama bagi seluruh stakeholder dari Sekolah XYZ sehingga perlu mengerahkan semua daya upaya untuk mencapai kepuasan yang tinggi bagi pelanggan (orang tua dan siswa). Dengan Customer Satisfaction yang terus meningkat akan menciptakan Customer Loyalty bagi Sekolah XYZ.

\section{DAFTAR PUSTAKA}

Cao, C., Chen, J. (2011). An Empirical Analysis of the Relationship Among the Service Quality, Customer Satisfaction and Loyalty of High Speed Railway Based on Structural Equation Model. Canadian Social Science. 7(4), 67-73.

Foedjiwati, Samuel, H., (2005). Pengaruh Kepuasan Konsumen terhadap Kesetiaan Merek (Studi Kasus Restoran The Prime Steak \& Ribs Surabaya). Jurnal Manajemen dan Kewirausahaan. 7, 74-82.

Hasan, A. (2009). Marketing. Media Pressindo. Yogyakarta.

Jogiyanto, H. M. (2005). Analisis dan Desain Sistem Informasi. Yogyakarta : ANDIYogyakarta.

Kotler P., Keller, K. L. (2012). Manajemen Pemasaran. Edisi 14. Jakarta: Penerbit Erlangga. (2007). Manajemen Pemasaran. Edisi 12 jilid 1. Jakarta: Penerbit Erlangga.

Kotler, P. (2005). Marketing Management (11th ed.). New Jersey: Pearson Education Inc.

Lupiyoadi, R., Hamdani, A. (2006). Manajemen Pemasaran Jasa. Jakarta: Salemba Empat.

McLeod, Jr., R. (2004). Sistem Informasi Manajemen: "Studi Sistem Informasi Berbasis Komputer". Jakarta: PT. Prenhallindo.

Nazir, M. (2005). Metodologi Penelitian. Bogor: Ghalia Indonesia.

Riduwan, Achmad, K. E. (2007). Cara Menggunakan dan Memakai Analisis Jalur (Path Analysis). Bandung: Penerbit Alfabeta.

Tjiptono, F. (2008). Service Management. Yogyakarta: Penerbit Andi.

Tjiptono, F., Chandra, G. (2005). Service, Quality, Satisfaction (Edisi ke-1 ed.). Yogyakarta: Penerbit Andi. 